\title{
Particle Characterisation and Grinding Behaviour of Gamma-Alumina Slurries Prepared in a Stirred Media Mill
}

\author{
Stephen Adegbite ${ }^{1}$ \\ ${ }^{1}$ Engineering \& Physical Sciences, University of Birmingham, Edgbaston, Birmingham, B15 2TT, UK \\ Correspondence: Stephen Adegbite, Division of Civil, Chemical \& Environmental Engineering, University of \\ Surrey, Guildford GU2 7XH, UK. Tel: 44-148-368-9312. E-mail: s.adegbite@surrey.ac.uk; \\ stephen_adegbite@hotmail.com
}

Received: October 30, $2012 \quad$ Accepted: November 20, $2012 \quad$ Online Published: December 12, 2012
doi:10.5539/jmsr.v2n1p135

\begin{abstract}
This paper investigates $\gamma$-alumina slurry preparation in a stirred media mill to develop protocols for the characterisation of slurries for coating onto monolithic catalyst supports. The relationship between the $\mathrm{pH}$ and the zeta potential of particles is determined. The $\gamma$-alumina particles are found to be optimally stabilised at a $\mathrm{pH}$ of 4 and zeta potential of $+41 \mathrm{mV}$. The grinding behaviour of $\gamma$-alumina particles inside the mill is determined in terms of the number of stress events $(\mathrm{SN})$, stress energy $(\mathrm{SE})$ and the specific energy $\left(\mathrm{E}_{\mathrm{m}, \mathrm{p}}\right)$. The visualisation of the particles at different stages of milling is done by scanning electron microscope (SEM). The results show that finer particles are produced by increasing milling duration from $0-240 \mathrm{~min}$ due to an increase in SN and that the use of smaller grinding media inside the mill produced finer particles due to an efficient consumption of $\mathrm{E}_{\mathrm{m}, \mathrm{p}}$.
\end{abstract}

Keywords: $\gamma$-alumina, characterisation, grinding, stabilisation, zeta-potential, morphology

\section{Introduction}

The emergence of the first cars equipped with monolith catalysts began in 1975 and today there are several hundred million monolith catalysts fitted in motor vehicles worldwide (Twigg, 2007). Emission levels from exhaust systems of modern passenger cars equipped with emission control catalysts are $90 \%$ lower than their 1960s counterparts. In addition, demand for emission control technology is constantly increasing worldwide due to greater need for motorised transportation, new legislation for deployment in developing countries and tighter emission standards aimed at future zero emissions (Twigg, 2006). These factors will invariably increase the competition in the catalyst industry for the development of technologies to enhance automotive catalytic functions (Collins \& Twigg, 2007; Jobson, 2004).

Manufacture of the monolith catalysts presents several challenges, the greatest of which is obtaining sufficient adhesion between the platinum group metal (PGM) inorganic slurry and the monolith support to prevent flaking or defects forming in the surface coating over the operating life of the component. The preparation path for the PGM inorganic slurry and coating of the monolith is shown in Figure 1. The inorganic slurry (commonly $\gamma$-alumina particles dispersed in water) is prepared in a stirred media mill to reach a desired particle size under $\mathrm{pH}$ controlled conditions to prevent aggregation. The resulting PGM slurry is then deposited onto the pre-oxidised monolith by a coating method (Cybulski \& Moulijn, 2006) to generate a substrate/washcoat composite, which is subsequently dried and calcined (Jia et al., 2007). The $\gamma$-alumina particles present in the inorganic slurry need to be sufficiently stabilised with a dispersant, and then fragmented in a stirred bead mill before the commencement of coating. The stabilisation of $\gamma$-alumina particles is necessary to prevent the van der Waals forces causing particle aggregation which affects the adhesion between the coating and the monolith surface.

A considerable number of studies (e.g. Adegbite, 2010; Avila et al., 2005; Germani et al., 2007; Jia et al., 2007) have shown that good coating adhesion can be promoted by using finer $\gamma$-alumina particles for coating monoliths. Therefore, the milling process should be targeted at producing $\gamma$-alumina particles of the desired particle size distributions (psds). The milling of $\gamma$-alumina slurries to obtain these distributions has been done in previous studies using various mill types: stirred media mill (Fadhel \& Frances, 2001); ball mill (Yang \& Sigmund, 2002) and the jet mill (Omura et al., 2005). Stirred media mills are increasingly used in many applications (e.g. pharmaceuticals, coatings, paints) for microgrinding, dispersion and disintegration of particles 
in the liquid phase (Fadhel \& Frances, 2001). Due to their increasing demand for producing ultra-fine particles making them advantageous compared to other mills, stirred bead mills have been the subject of a growing number of studies (Kwade, 2004; 2002; 1999).

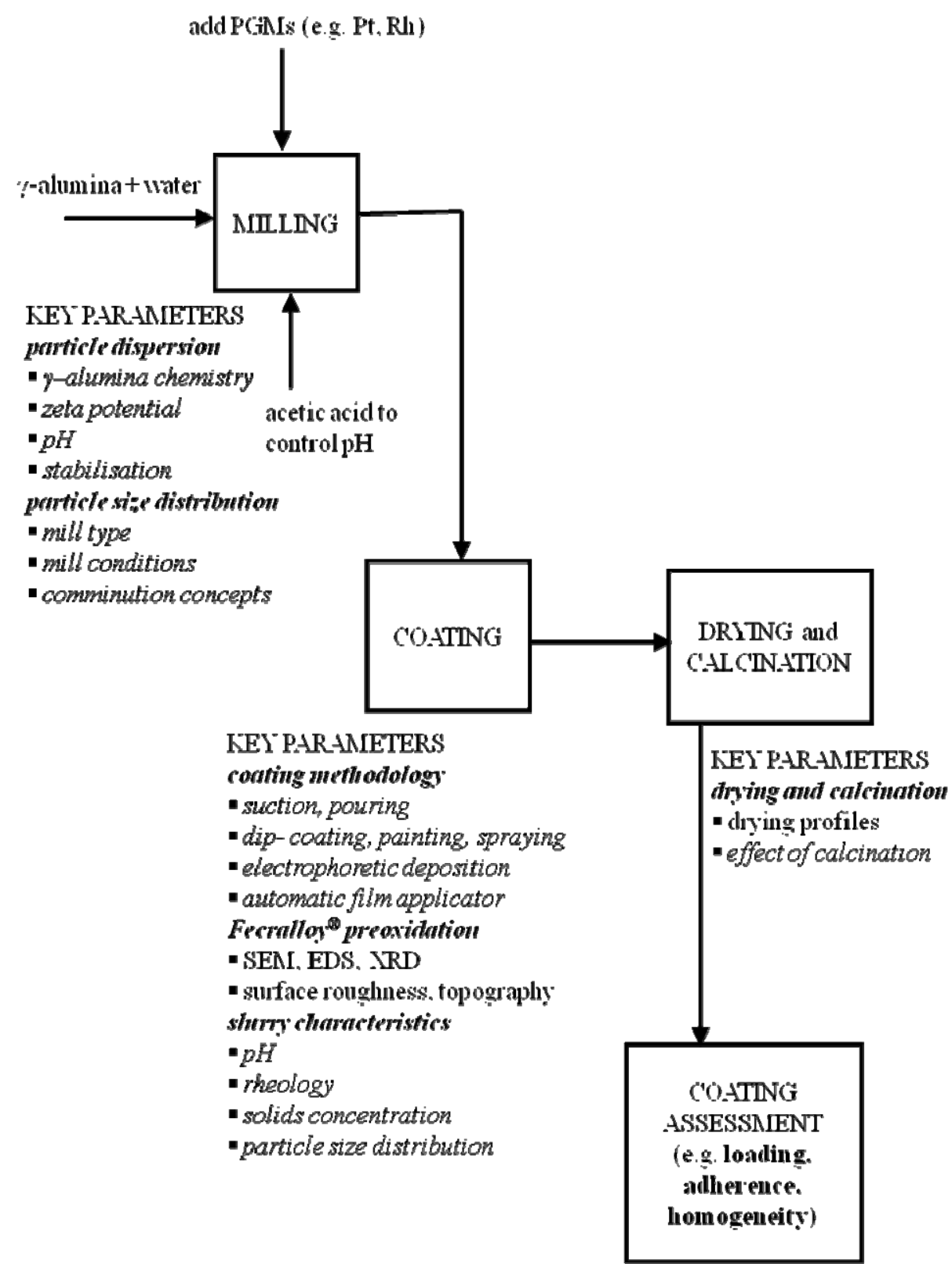

Figure 1. A detailed preparation path for coatings

The $\gamma$-particles are mixed and fragmented by the mechanical agitation produced inside these mills by the moving shafts and the grinding media. The grinding behaviour of $\gamma$-alumina particles in a stirred media mill is determined by 3 factors (Kwade, 2003; 2002; 1999):

(a) Stress number $(S N)$ : the average number of stress events on each product particle in a batch grinding process.

(b) Stress energy (SE): the energy at each stress event.

(c) Specific energy $\left(E_{m, p}\right)$ : the energy per unit mass consumed by the grinding media for comminution of product particles. Due to the various forms of energy dissipation, it is known that only a small fraction of the 
energy consumed by the mill is used by the grinding media for the comminution of product particles. Figure 2 shows the different forms by which energy is lost in a stirred media mill.

However, the effect of milling duration on the psds of ground $\gamma$-alumina particles have not been properly investigated in the literature. Even more so there is no clarity as to how the use of grinding media of different diameters influences the psds of ground particles. A good understanding of how these parameters influence the psds of ground particles is useful for the preparation of slurries of the desired specifications at the minimum energy input. Therefore, the work in this paper is aimed at determining: (i) the relationship between the slurry $\mathrm{pH}$ and the zeta potential of $\gamma$-alumina particles; and (ii) how the slurry and milling characteristics affect the psds of the ground particles by considering the basic comminution factors.

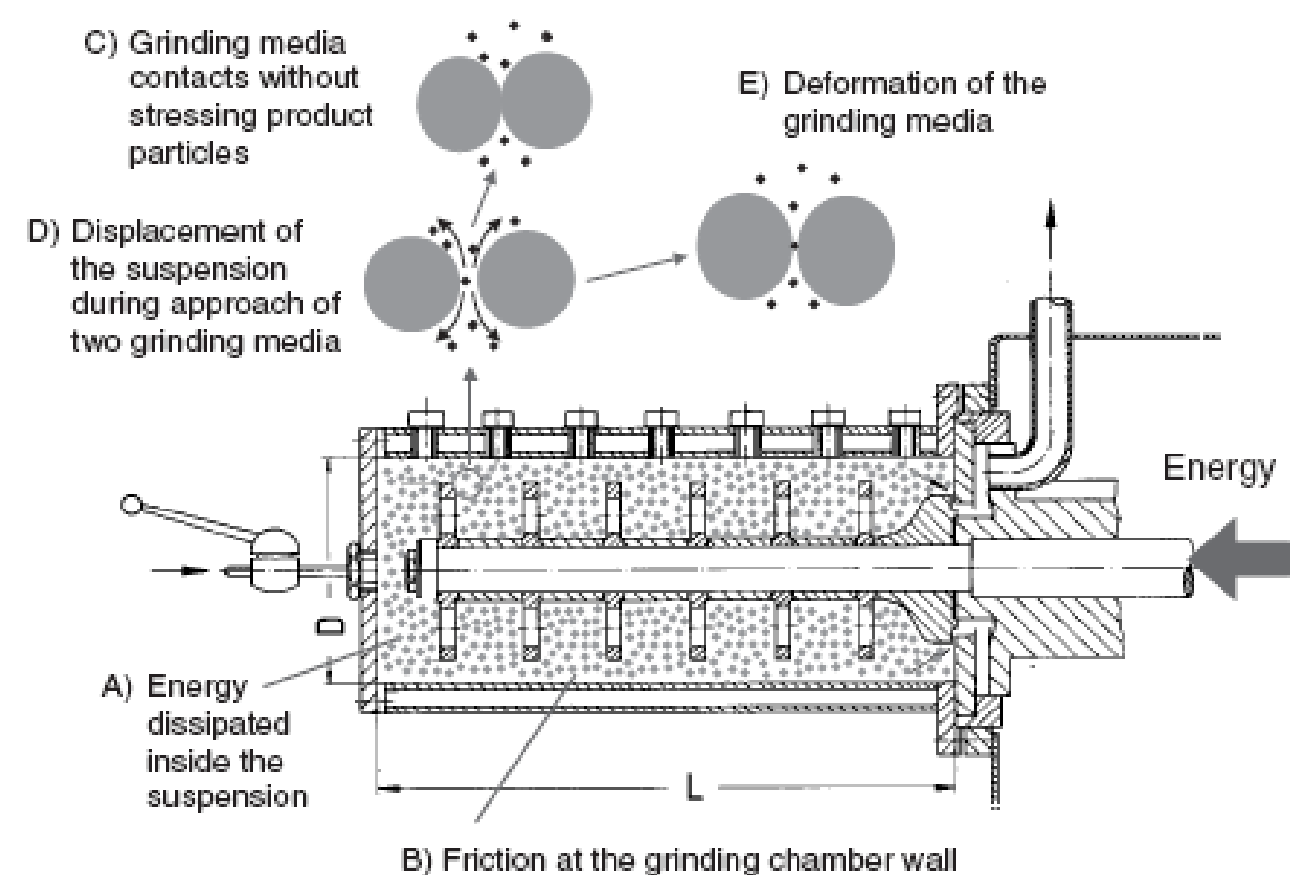

Figure 2. Energy loss in a stirred bead mill (Kwade, 2003)

\section{Materials and Methods}

\subsection{Slurry Preparation and Characterisation}

The $\gamma$-alumina (PURALOX SCFa-140, Sasol UK) was supplied as a 98\% purity white powder with a specific surface area of $142 \mathrm{~m}^{2} \mathrm{~g}^{-1}$. A summary of the properties of the alumina particles is shown in Table 1. The slurries were prepared by mixing $\gamma$-alumina powder in double-distilled water, with the $\mathrm{pH}$ adjusted to a starting value of 4 using acetic acid solution (1M; Fischer Scientific, UK). The slurry $\mathrm{pH}$ was measured using a $\mathrm{pH}$ meter (Mettler-Toledo, UK). The slurry particles were then comminuted at $40 \mathrm{wt} \%$ solids concentration inside a stirred bead mill of volume 1.2 litres (Union Process, USA). Spherical zirconia grinding media of 1 or 5 mm diameter were added at $40 \% \mathrm{vol}$ and the milling time was set to $10-240$ minutes at $500 \mathrm{rpm}$. The temperature was maintained between $20-22^{\circ} \mathrm{C}$ using a cooling jacket. The particle size distributions (psds) of the slurries obtained were determined using a laser diffraction instrument (Malvern Mastersizer, 2000). A schematic representation of the particle diameters measured by the Mastersizer 2000 is given in Figure 3, where $\mathrm{d}_{0.1}, \mathrm{~d}_{0.5}$ and $\mathrm{d}_{0.9}$ refer to the $10 \%, 50 \%$ and $90 \%$ percentile volume diameters respectively. 
Table 1. Properties of $\gamma$-alumina powder

\begin{tabular}{ll}
\hline Typical properties & Values \\
\hline Appearance & White powder \\
Type & Calcined alumina \\
Purity (\%) & 98 \\
Odour & None \\
Thermal modifiers $\left(\mathrm{e} . \mathrm{g} . \mathrm{La}^{2+}\right)$ & None \\
Designated symbol & PURALOX SCFa-140 \\
Pore volume $\left(\mathrm{cm}^{3} \mathrm{~g}^{-1}\right)$ & 0.50 \\
Diameter: $\mathrm{d}_{0.1} ; \mathrm{d}_{0.5} ; \mathrm{d}_{0.9}(\mu \mathrm{m})$ & $4.6 ; 20.7 ; 43.4$ \\
Loose bulk density $\left(\mathrm{kgm}^{-3}\right)$ & 800 \\
Surface area $24 \mathrm{~h} / 1100^{\circ} \mathrm{C}\left(\mathrm{m}^{2} \mathrm{~g}^{-1}\right)$ & 15 \\
\hline
\end{tabular}

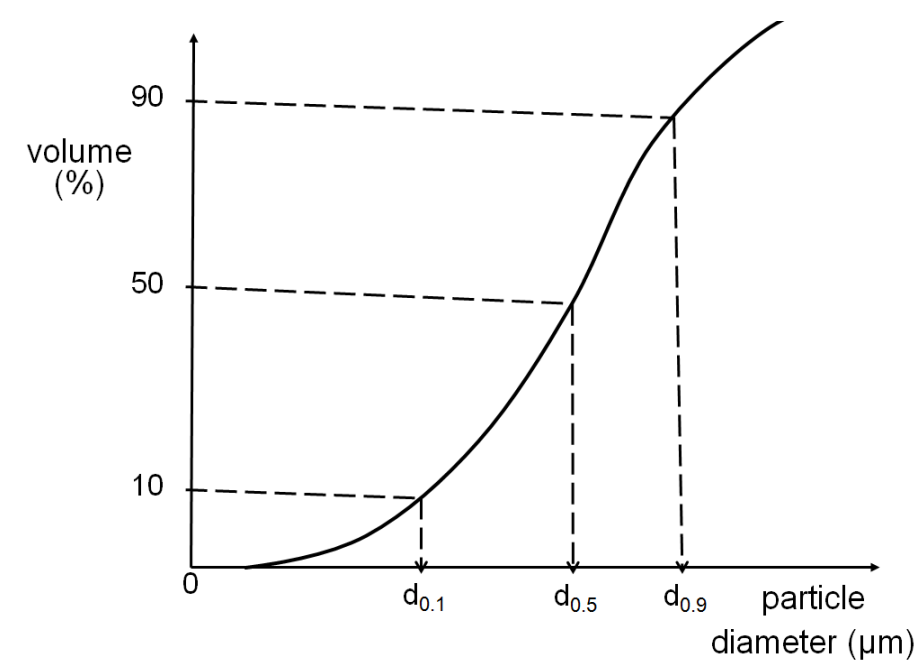

Figure 3. Schematic representation of diameters $\mathrm{d}_{0.1}, \mathrm{~d}_{0.5}$ and $\mathrm{d}_{0.9}$

\subsection{Zeta Potential Measurements by Acoustosizer and Zetamaster}

The relationship between the zeta potential of $\gamma$-alumina and slurry $\mathrm{pH}$ was determined by electroacoustics and electophoresis using the Acoustosizer (Colloidal dynamics, USA) and Zetamaster (Malvern Instruments, UK) respectively. The aqueous solutions of $\mathrm{HCl}$ (1M; Fischer Scientific, UK) and $\mathrm{NaOH}$ (1M; Merck Chemicals, UK) were used to alter the slurry $\mathrm{pH}$. The background electrolyte used for the Acoustosizer measurements was $\mathrm{KCl}$ solution $\left(10^{-3} \mathrm{M}\right.$; Fischer Scientific, UK). The Acoustosizer measurements were recorded for every $1 \mathrm{ml}$ of added $\mathrm{HCl}$ or $\mathrm{NaOH}$ (Greenwood \& Kendall, 2000). As electrophoresis only functions for dilute systems, the slurry was initially diluted to one-twelfths its initial concentration to prevent clogging of the equipment pipes. All the water used was double-distilled. The slurry was allowed to equilibrate at $25^{\circ} \mathrm{C}$ before measurements were taken.

\section{Results and Discussion}

\subsection{Zeta Potential Measurements}

The relationship between the zeta potential of $\gamma$-alumina particles and the slurry $\mathrm{pH}$ as measured by the Acoustosizer and Zetamaster is shown in Figure 4, while the particles electrokinetic sonic amplitude (ESA) diameter as a function of $\mathrm{pH}$ taken by the Acoustosizer is shown in Figure 5. The ESA technique is such that when an alternating electrical potential was applied to the slurry, it caused the particles to vibrate in a manner that depends on their diameter and on the zeta potential at the frequency of the applied field. When there is a density difference between the particles and the aqueous suspension, this motion would generate an alternating acoustic wave of the same frequency as the applied field. This phenomenon is called the ESA effect and the particle diameter measured is termed the ESA diameter (Sarraf \& Herbig, 2008). These results clearly show the strong dependence of the zeta potential and the ESA diameter of particles on slurry $\mathrm{pH}$. The particles become charged when dispersed in the aqueous slurry, which results in electrostatic repulsive forces between the particles and counter-ions due to overlap of similarly charged electric double layers. The electrostatic forces, quantified by 
zeta potential, act opposite to the attractive long-range van der Waals forces. The particles experience the overall effect of the electrostatic and van der Waals forces (Binner \& McDermott, 2006; Kasprzyk-Hordern, 2004).

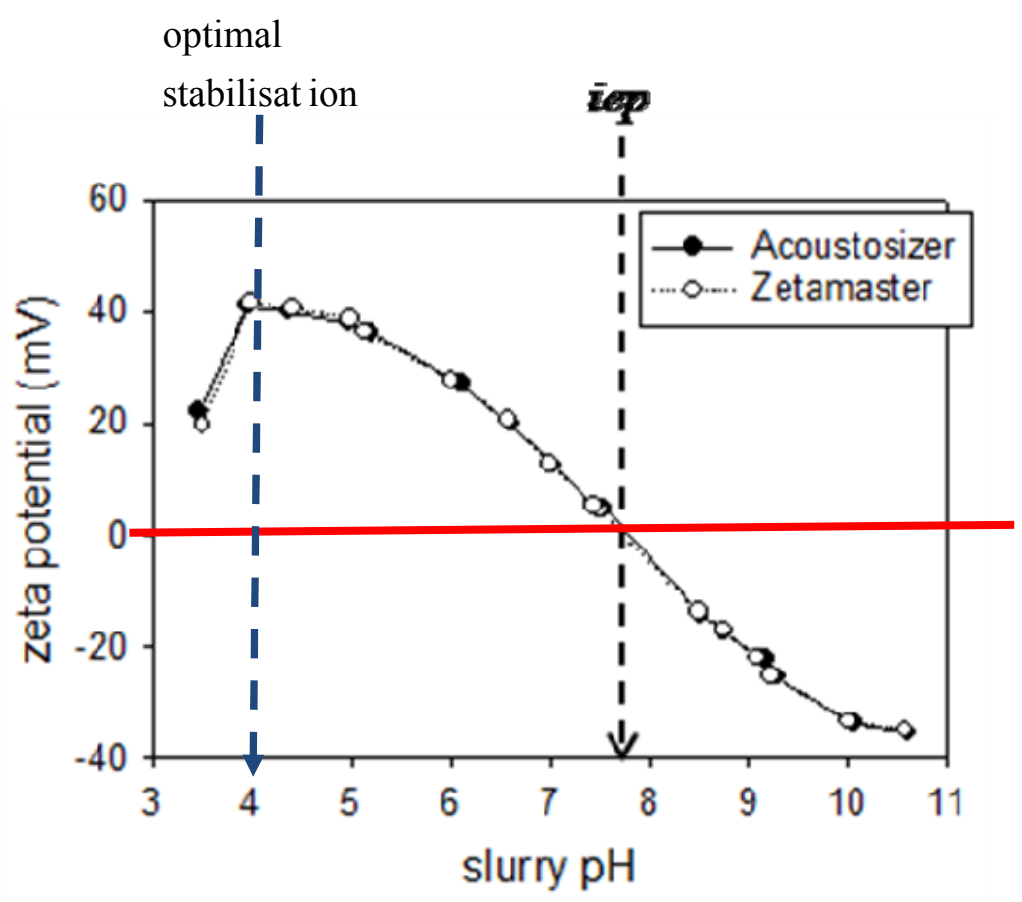

Figure 4. Zeta potential of $\gamma$-alumina particles as a function of slurry $\mathrm{pH}$

By convention slurries having zeta potential greater than $|30| \mathrm{mV}$ are considered as sufficiently stabilised (Greenwood, 2003). It is shown in Figure 4 that the iep (i.e. pH at which zeta potential equals zero) of the particles is 7.7. This is the $\mathrm{pH}$ at which the particles were furthest from stabilisation as the slurry was comprised of aggregates. The natural $\mathrm{pH}$ of $\gamma$-alumina particles was found to be at 9.1 ; the zeta potential at this point is -23 $\mathrm{mV}$. This iep and the natural $\mathrm{pH}$ values are in good agreement with previous measurements in the literature which were 7.7 - 7.9 and 9.0 - 9.2 respectively (Binner \& McDermott, 2006; Agrafiotis \& Tsetsekou, 2000; Nowack et al., 1996; Tijburg et al., 1991). As the slurry pH gets close to the iep, the van der Waals attraction forces between particles become dominant, leading to particle aggregation and less stabilisation. At extreme $\mathrm{pH}$ of less than 4 however, there exists flocculation in the slurry due to overlap of double layers which causes reduction in the zeta-potential of particles. The ESA measurements in Figure 5 followed the same trend showing an increase in particle diameter due to particle aggregation as the slurry $\mathrm{pH}$ nears the iep. However, the ESA measurements close to the iep should be treated with caution based on the minimal stabilisation in the slurry (Greenwood, 2003). The optimal stabilisation of particles was achieved at $\mathrm{pH}$ of 4 and this is in accordance with the values in the literature in the range of $3.8-4.5$ (Binner \& McDermott, 2006; Agrafiotis \& Tsetsekou, 2000; Nowack et al., 1996; Tijburg et al., 1991). This $\mathrm{pH}$ value corresponds to a zeta potential of $+41 \mathrm{mV}$. Both the Acoustosizer and the Zetamaster measurements showed strong correlation throughout the $\mathrm{pH}$ interval investigated, confirming the reliability of the data from the two sets of equipment. 


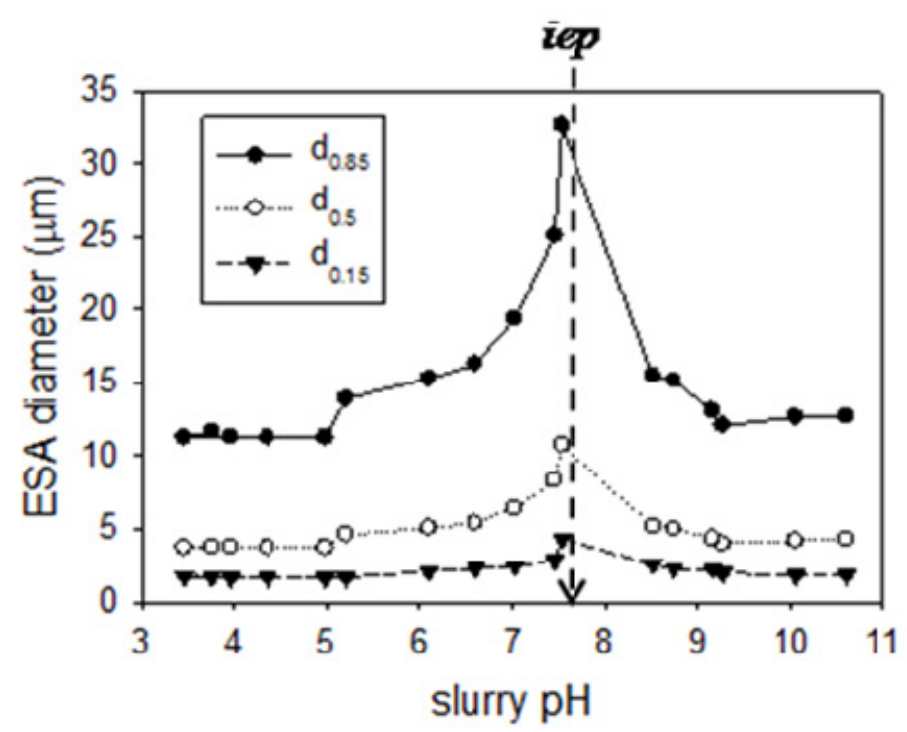

Figure 5. ESA diameter of $\gamma$-alumina particles as a function of slurry $\mathrm{pH}$

\subsection{Effect of Milling Duration on Particle Size Distribution}

The diameters $\mathrm{d}_{0.1}, \mathrm{~d}_{0.5}$ and $\mathrm{d}_{0.9}$ of the slurries at $40 \mathrm{wt} \%$ solids concentration after milling for $0-240$ min are shown in Table 2, while their psds are shown in Figure 6. These results show a general decrease in the particle diameters with the increase in milling time.

Table 2. Particle diameters for slurries at $40 \mathrm{wt} . \%$ concentration after milling for $0-240 \mathrm{~min}$

\begin{tabular}{llll}
\hline Milling time $(\mathrm{min})$ & $\mathrm{d}_{0.1}(\mu \mathrm{m})$ & $\mathrm{d}_{0.5}(\mu \mathrm{m})$ & $\mathrm{d}_{0.9}(\mu \mathrm{m})$ \\
\hline 0 & 4.63 & 20.70 & 43.43 \\
10 & 2.64 & 15.16 & 33.42 \\
20 & 1.90 & 9.56 & 23.02 \\
40 & 1.71 & 6.13 & 16.47 \\
60 & 1.34 & 4.36 & 12.74 \\
240 & 1.09 & 2.76 & 7.82 \\
\hline
\end{tabular}

This behaviour can be explained by considering the relationship between the stress number (SN) and the bead milling time $\left(\mathrm{t}_{\mathrm{m}}\right)$ in Equation 1

$$
S N \propto \frac{\varphi_{G M}(1-\varepsilon)}{\left[1-\varphi_{G M}(1-\varepsilon)\right]} \frac{N t_{m}}{d_{G M}^{2}} \frac{\rho_{a l}}{\rho_{\text {slurry }} c_{a l}}
$$

where

$$
\begin{aligned}
& S N=\text { number of stress events }(-) \\
& \varepsilon=\text { porosity of the bulk of the media }(-) \\
& \rho_{a l}=\text { density of } \gamma \text {-alumina particles }\left(\mathrm{kg} \mathrm{m}^{-3}\right) \\
& t_{m}=\text { milling time (s) } \\
& \rho_{\text {slurry }}=\text { slurry density }\left(\mathrm{kg} \mathrm{m}^{-3}\right) \\
& c_{a l}=\gamma \text {-alumina solids concentration }(\mathrm{wt} \%) \\
& N=\text { shaft speed (rpm) } \\
& d_{G M}=\text { diameter of grinding media }(\mu \mathrm{m}) \\
& \varphi_{G M}=\text { media load }(\%)
\end{aligned}
$$




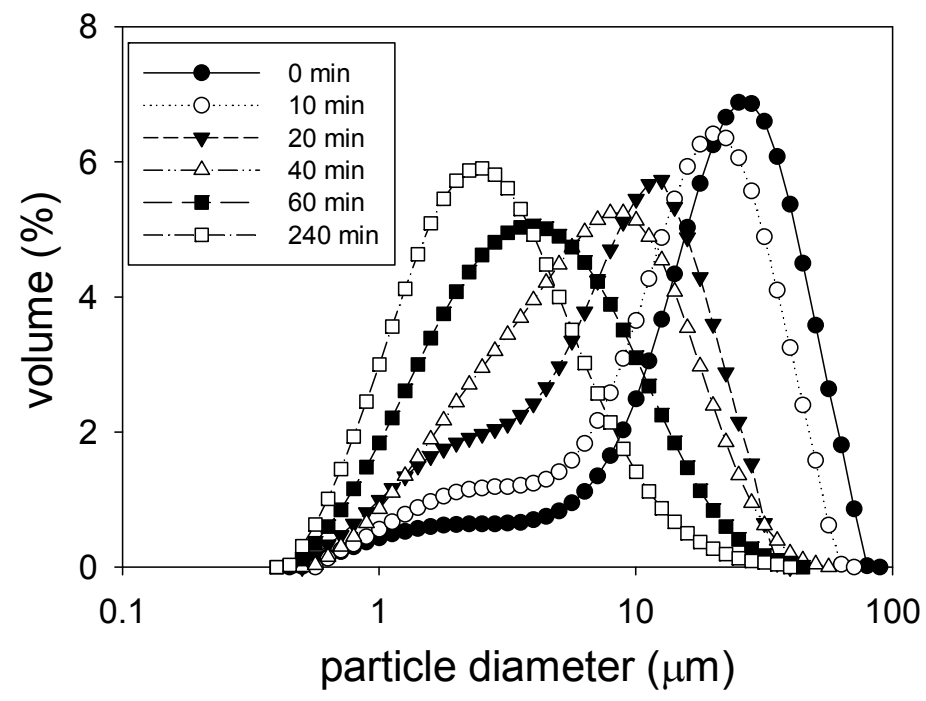

Figure 6. Frequency particle size distributions of slurries of $40 \mathrm{wt} \%$ solids concentration after milling for $0-240$ $\min (5 \mathrm{~mm}$ media diameter)

It is clear that, with all other parameters constant, stress number $\mathrm{SN}$ is directly proportional to the milling time $\mathrm{t}_{\mathrm{m}}$, thus meaning that there was an increase in the number of stress events with the increase in milling. As a result of this, there is a systematic shift of the psd curves towards the left as smaller particles were being produced. This is highlighted by the presence of bimodal distributions after milling for 10 and $20 \mathrm{~min}$, but these distributions subsequently became unimodal at milling times more than $40 \mathrm{~min}$. Furthermore, it is shown from Table 2 and Figure 6 that all the slurries milled for at least 60 min conformed to a set target of $\mathrm{d}_{0.9}<15 \mu \mathrm{m}$ and $\mathrm{d}_{0.1}<2 \mu \mathrm{m}$. The $\gamma$-alumina particles milled for $60 \mathrm{~min}$ (shown in Figure 7b) appeared finer and irregularly shaped, while the as-received $\gamma$-alumina particles (shown in Figure $7 \mathrm{a}$ ) appeared large, roundly shaped and not fractured.
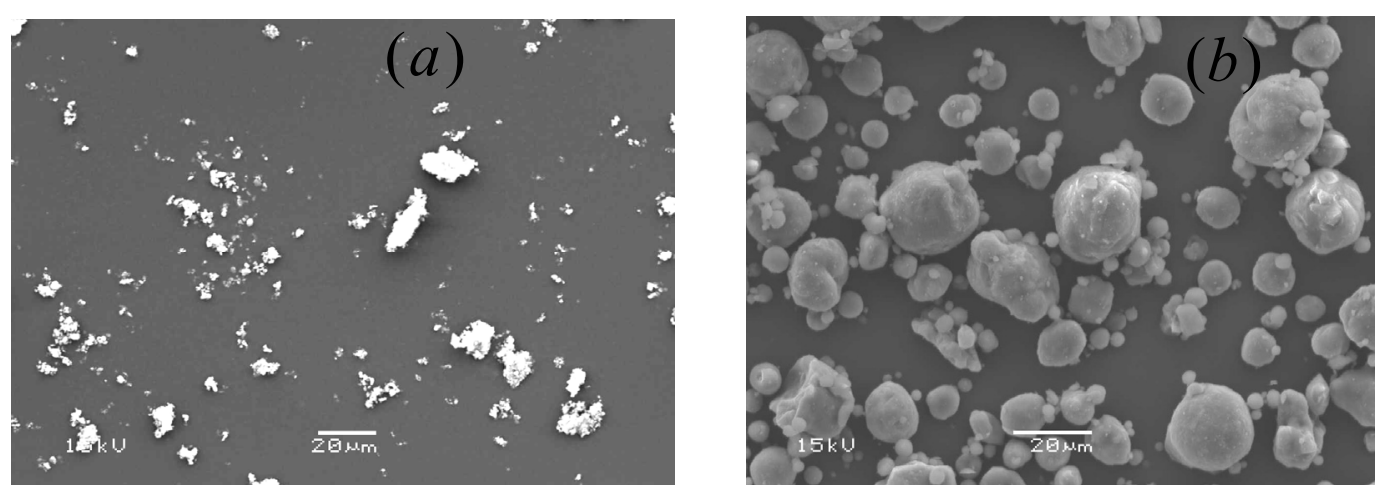

Figure 7. SEM images of $\gamma$-alumina particles: (a) as-received; and (b) milled for 60 min using media of $5 \mathrm{~mm}$ diameter

A further understanding of the fragmentation behaviour can be obtained by taking account of the rate of decrease in the particle diameters with the increase in milling time (Figure 8). It is shown that large particles have a higher rate of size reduction compared to small particles. This fact is evidenced by the steep slope of $\mathrm{d}_{0.9}$ curve compared to those of $\mathrm{d}_{0.5}$ and $\mathrm{d}_{0.1}$. Similarly, the slope of $\mathrm{d}_{0.5}$ curve is steeper than that of $\mathrm{d}_{0.1}$. The reason for this development is that large particles were fragmented into smaller ones without regeneration. On the contrary, the smaller particles were being continuously regenerated from the fragments of large particles. 


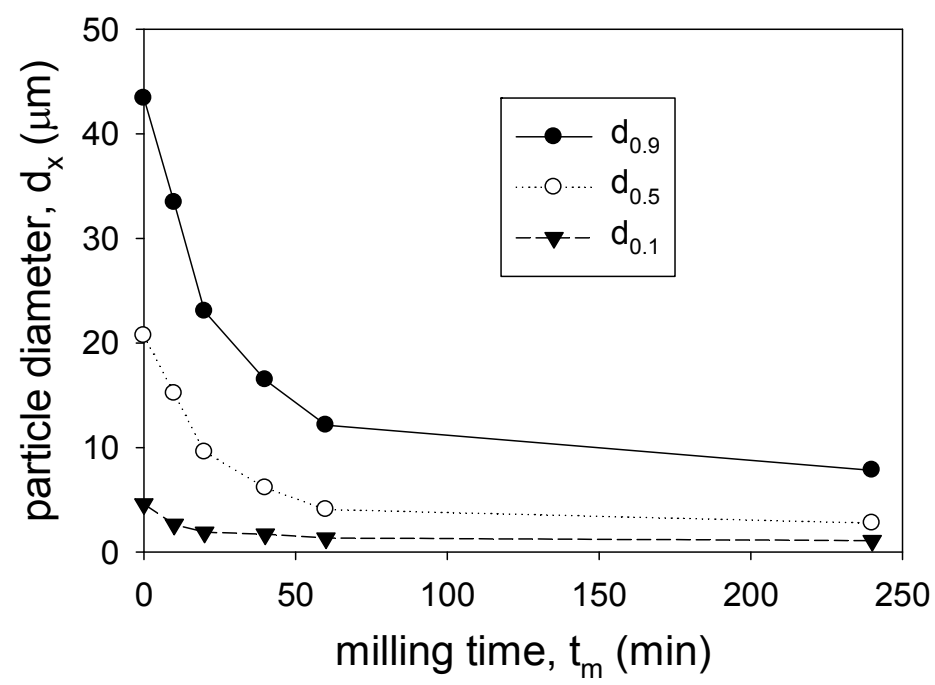

Figure 8. Systematic decrease in the slurry particle diameters with the increase in milling time

\subsection{Effect of Grinding Media Diameter on Particle Size Distribution}

The slurry psds at the solids concentration of $40 \mathrm{wt} \%$ after milling separately for $0-240 \mathrm{~min}$ using 1 and $5 \mathrm{~mm}$ media diameters are shown in Figures 9 and 10 respectively. The systematic shift of the psds curves in Figures 9 and 10 towards the left is a confirmation that smaller particles were being produced in the stirred mill. The bimodal distributions obtained in Figure 9 at milling times of 10 and 20 min which later became unimodal after further milling shows the transition to formation of finer particles. The particle diameters obtained from both media diameters are jointly presented in Table 3 . It is shown that the use of a $1 \mathrm{~mm}$ media diameter resulted in finer particles at equal milling time compared to using a $5 \mathrm{~mm}$ media diameter. The use of $1 \mathrm{~mm}$ media diameter enabled the production of slurry which conform to a set target of $\mathrm{d}_{0.9}<15 \mu \mathrm{m}$ and $\mathrm{d}_{0.1}<2 \mu \mathrm{m}$ at a reduced time of $40 \mathrm{~min}$, in comparison to the $60 \mathrm{~min}$ taken by the $5 \mathrm{~mm}$ media.

Table 3. Particle diameters for slurries at $40 \mathrm{wt} . \%$ concentration after milling for $0-240 \mathrm{~min}$ using different grinding media diameters

\begin{tabular}{lllllll}
\hline \multirow{2}{*}{$\begin{array}{l}\text { Milling } \\
\text { time }(\min )\end{array}$} & \multicolumn{3}{l}{$5 \mathrm{~mm}$ diameter } & \multicolumn{3}{l}{$\mathrm{mm}$ diameter } \\
\cline { 2 - 7 } & $\mathrm{d}_{0.1}(\mu \mathrm{m})$ & $\mathrm{d}_{0.5}(\mu \mathrm{m})$ & $\mathrm{d}_{0.9}(\mu \mathrm{m})$ & $\mathrm{d}_{0.1}(\mu \mathrm{m})$ & $\mathrm{d}_{0.5}(\mu \mathrm{m})$ & $\mathrm{d}_{0.9}(\mu \mathrm{m})$ \\
\hline 0 & 4.63 & 20.70 & 43.43 & 4.63 & 20.70 & 43.43 \\
10 & 2.64 & 15.16 & 33.42 & 1.92 & 11.98 & 30.03 \\
20 & 1.90 & 9.56 & 23.02 & 1.79 & 7.38 & 17.80 \\
40 & 1.71 & 6.13 & 16.47 & 1.25 & 3.39 & 9.92 \\
60 & 1.34 & 4.36 & 12.74 & 1.01 & 2.27 & 6.35 \\
240 & 1.09 & 2.76 & 7.82 & 0.45 & 1.12 & 3.67 \\
\hline
\end{tabular}

The effect of grinding media diameter on the ground product can be thoroughly investigated by considering the changes to the key comminution parameters: stress number (SN), stress energy (SE) and specific energy $\left(E_{m, p}\right)$ during the milling process. Given that all other operating parameters are constant except the grinding media diameter $\mathrm{d}_{\mathrm{GM}}$, then Equation (1) is reduced to Equation (2).

$$
S N \propto \frac{t_{m}}{d_{G M}^{2}}
$$




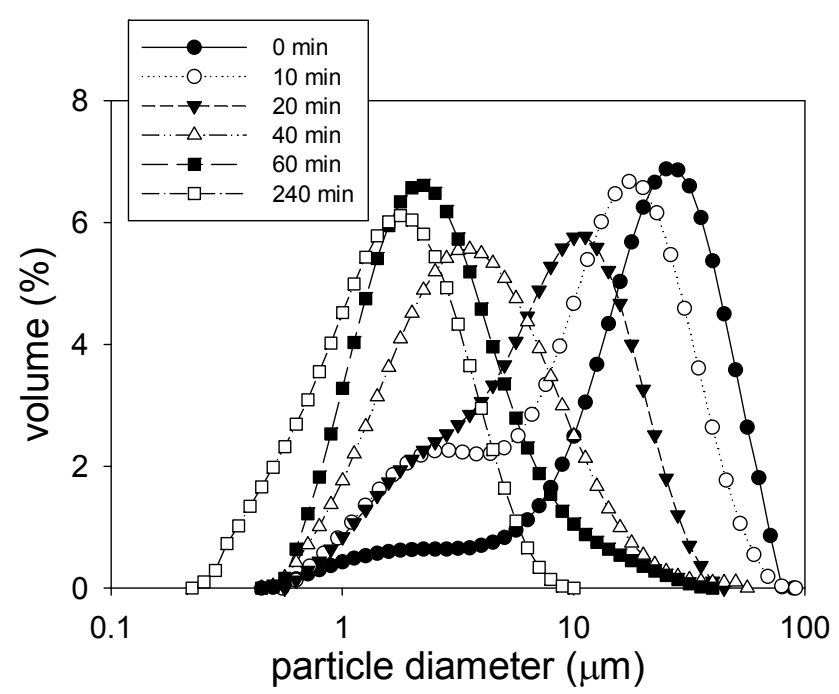

Figure 9. Frequency particle size distributions of slurries of $40 \mathrm{wt} \%$ solids concentration after milling for $0-240$ $\min (1 \mathrm{~mm}$ media diameter)

The stress energy SE is given by Equations (3) and (4):

$$
\begin{aligned}
& S E \propto S E_{G M}=d_{G M}^{3} \rho_{G M} v_{t}^{2} \\
& S E \propto S E_{G M} \propto d_{G M}^{3}
\end{aligned}
$$

where

$S E=$ stress energy $(\mathrm{J})$

$S E_{G M}=$ stress energy of grinding media $(\mathrm{J})$

$v_{t}=$ circumferential speed of the shaft $\left(\mathrm{m} \mathrm{s}^{-1}\right)$

$\rho_{G M}=$ density of grinding media

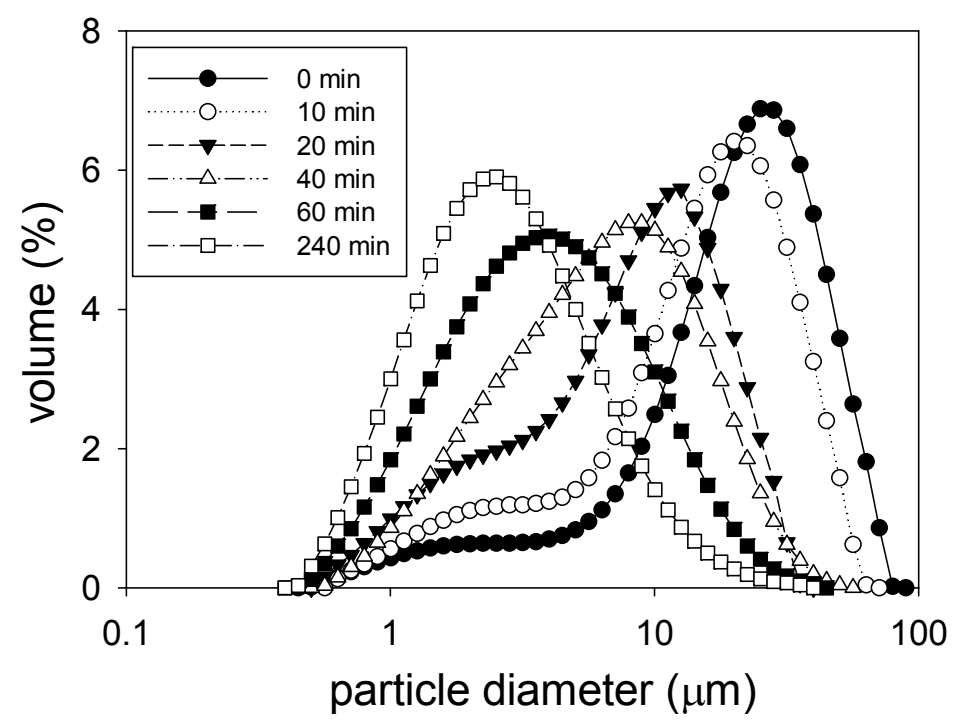

Figure 10. Frequency particle size distributions of slurries of $40 \mathrm{wt} \%$ solids concentration after milling for 0 $240 \mathrm{~min}$ ( $5 \mathrm{~mm}$ media diameter) 


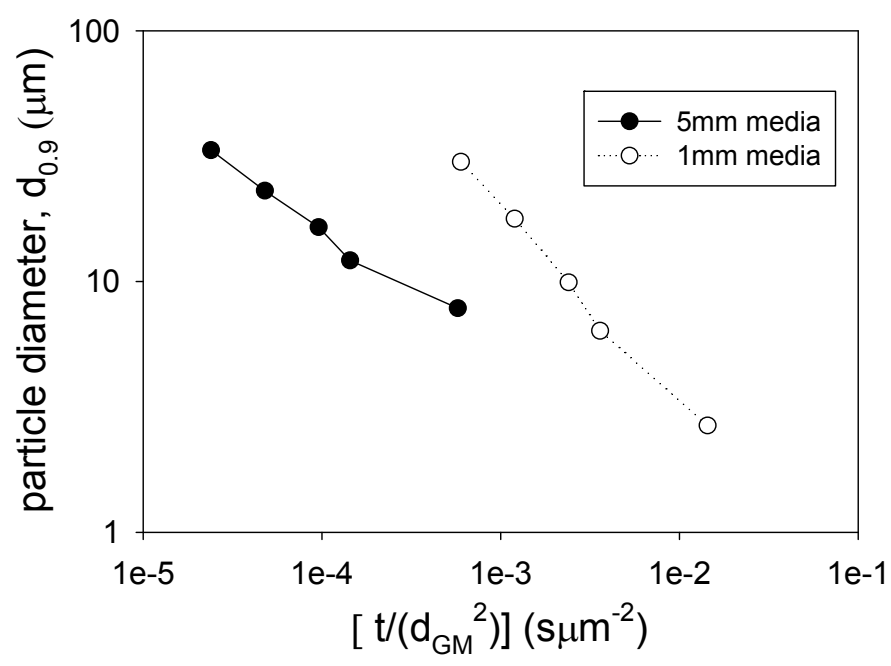

Figure 11. Effect of media diameter on SN

Figure 11 represents the relationship between particle diameter of the ground products and $\mathrm{SN}$ according to Equation (2). Similarly, stress energies $\mathrm{SE}_{1}$ and $\mathrm{SE}_{5}$ for $1 \mathrm{~mm}$ and $5 \mathrm{~mm}$ media have this relationship:

$$
\frac{S E_{5}}{S E_{1}}=\frac{d_{G M 5}^{3}}{d_{G M 1}^{3}}=\frac{5^{3}}{1^{3}}=125 \text { times }
$$

Where

$S E_{1}$ and $d_{G M 1}$ represent the stress energy $(\mathrm{J})$ and diameter $(\mathrm{mm})$ for $1 \mathrm{~mm}$ media

$S E_{5}$ and $d_{G M 5}$ represent the stress energy (J) and diameter $(\mathrm{mm})$ for the $5 \mathrm{~mm}$ media

It is shown in Figure 11 that the stress number SN increased with the decrease in media diameter, while on the other hand Equation (5) shows that the stress energy SE increased with the increase in media diameter. Since the use of $1 \mathrm{~mm}$ media diameter resulted in smaller particle diameters compared to the $5 \mathrm{~mm}$ media, there is strong evidence to show that the SN effect appeared dominant on the SE effect in this case. But the specific energy $E_{m, p}$ is a measure of both $\mathrm{SN}$ and $\mathrm{SE}$ as indicated in Equation (6):

$$
E_{m, p}=\frac{S N_{M} \cdot \overline{S E}}{m_{a l}}=v_{E} E_{m, M}
$$

where

$S N_{M}=$ total number of stress events (-)

$\overline{S E}=$ mean stress energy $(\mathrm{J})$

$E_{m, M}=$ total specific energy consumption by the mill $\left(\mathrm{J} \mathrm{kg}^{-1}\right)$

$m_{a l}=$ mass of $\gamma$-alumina particles $(\mathrm{kg})$

$v_{E}=$ energy transfer factor (-) which account for the energy loss

Also $E_{m, p}$ is also given by (Fadhel and Frances, 2001):

$$
E_{m, p}=\frac{v_{E} N^{3} \rho_{\text {slurry }} \rho_{a l} D^{5} t_{m} P o}{m_{a l}}
$$

Where

$P o=$ power number $(-)$ 
$D=$ shaft diameter $(\mathrm{m})$

Given that all other operation parameters are constant except the media diameter, therefore a ratio of the specific energy to the power number is given by (Fadhel \& Frances, 2001):

$$
\frac{E_{m, p}}{P o} \propto N^{3} t_{m}
$$

This very useful relationship in Equation (8) can be used as a basis for describing how efficiently the energy consumed by the rotating shaft was translated into specific energy $E_{m, p}$ for both media diameters (Fadhel \& Frances, 2001). Figure 12 shows clearly that energy was consumed more efficiently in the mill for particle comminution when the $1 \mathrm{~mm}$ media diameter was used because smaller particle diameters were produced at the same $E_{m, p} / P o$ input throughout the milling process compared to the $5 \mathrm{~mm}$ media. This is a confirmation that 1 $\mathrm{mm}$ media had an overall favourable effect on the comminution than the $5 \mathrm{~mm}$ media.

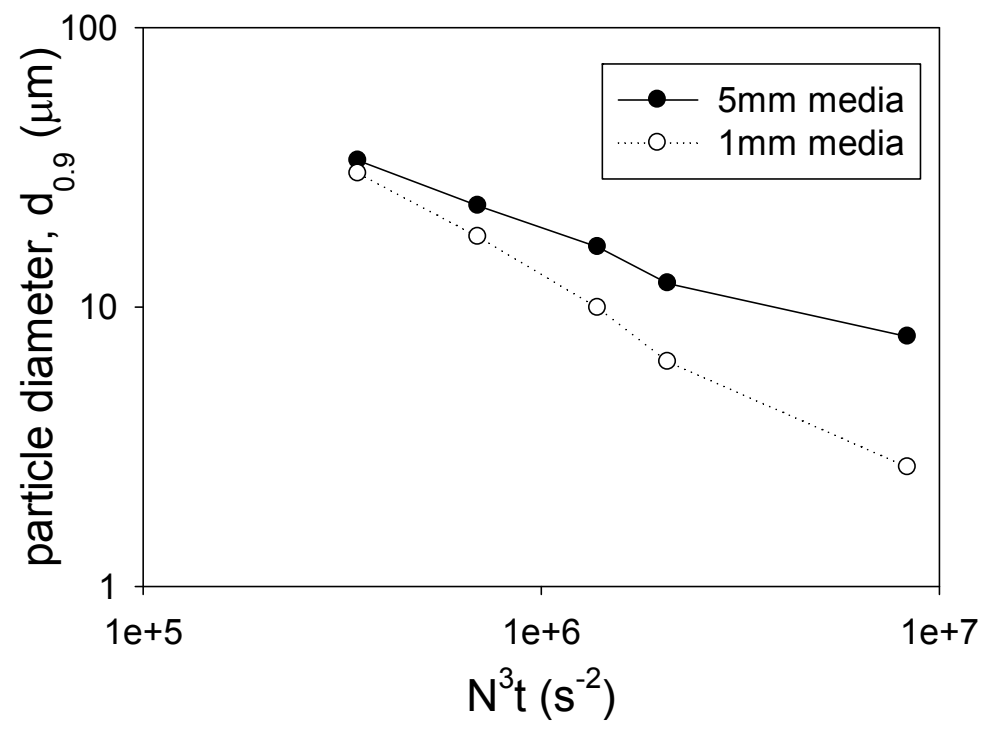

Figure 12. Particle diameter $\mathrm{d}_{0.9}$ as a function of $\mathrm{N}^{3} \mathrm{t}$

\section{Conclusions}

The effect of $\mathrm{pH}$ on $\gamma$-alumina stabilisation had been determined by zeta potential measurements. The iep point and the natural $\mathrm{pH}$ of $\gamma$-alumina were found at 7.7 and 9.1 respectively. The $\mathrm{pH}$ which produced optimal stabilisation (i.e. at $\zeta=+41 \mathrm{mV}$ ) was determined as 4 . The slurries achieved stabilisation through the electrostatic repulsion of the charged particles. The stress number SN, stress energy SE and specific energy $\mathrm{E}_{\mathrm{m}, \mathrm{p}}$ are revealed as the comminution factors which govern the grinding behaviour of $\gamma$-alumina particles in a stirred media mill. The ground particles showed a decrease in particle diameters as a milling duration increased from 0 - $240 \mathrm{~min}$ due to the increase in the stress number SN. The use of $1 \mathrm{~mm}$ media diameter resulted in the production of finer particles due to efficient consumption of specific energy $\mathrm{E}_{\mathrm{m}, \mathrm{p}}$ for particle comminution compared to the $5 \mathrm{~mm}$ media. The differences in SEM images of the particles before and after milling confirmed the grinding behaviour as the as-received particles changed from round to finer and irregularly shaped fragments.

\section{Acknowledgements}

This research was supported by the Engineering and Physical Sciences Research Council (EPSRC) and Johnson Matthey Plc. The views expressed in this article are those of the author and do not necessarily reflect the views of the sponsors.

\section{References}

Adegbite, S. A. (2010). Coating of catalyst supports - links between slurry characteristics, coating process and final coating quality. PhD Thesis (pp. 152-178). Birmingham, UK: University of Birmingham. Retrieved from http://etheses.bham.ac.uk/920/ 
Agrafiotis, C., \& Tsetsekou, A. (2000). The effect of processing parameters on the properties of g-alumina washcoats deposited on ceramic honeycombs. Journal of Materials Science, 35(4), 951-960. http://dx.doi.org/10.1023/a:1004762827623

Avila, P., Montes, M., \& Miro, E. E. (2005). Monolithic reactors for environmental applications - a review on preparation technologies. Chemical Engineering Journal, 109(1-3), 11-36. http://dx.doi.org/10.1016/j.cej.2005.02.025

Binner, J. G. P., \& McDermott, A. M. (2006). Rheological characterisation of ammonium polyacrylate dispersed, concentrated alumina suspensions. Ceramics International, 32(7), 803-810. http://dx.doi.org/10.1016/j.ceramint.2005.06.004

Collins, N. R., \& Twigg, M. V. (2007). Three-way catalyst emissions control technologies for spark-ignition engines - recent trends and future developments. Topics in Catalysis, 42-43, 323-332. http://dx.doi.org/10.1007/s11244-007-0199-6

Cybulski, A., \& Moulijn, J. A. (2006). Structured catalysis and reactors (2nd ed.). London: Taylor \& Francis.

Fadhel, H. B., \& Frances, C. (2001). Wet batch grinding of alumina hydrate in a stirred bead mill. Powder Technology, 119(2-3), 257-268. http://dx.doi.org/10.1016/S0032-5910

Germani, G., Stefanescu, A., Schuurman, Y., \& van Veen, A. C. (2007). Preparation and characterization of porous alumina-based catalyst coatings in microchannels. Chemical Engineering Science, 62(18-20), 5084-5091. http://dx.doi.org/10.1016/j.ces.2007.02.034

Greenwood, R. (2003). Review of the measurement of zeta potentials in concentrated aqueous suspensions using electroacoustics. Advances in Colloid and Interface Science, 106, 55-81. http://dx.doi.org/10.1016/S0001-8686

Greenwood, R., \& Kendall, K. (2000). Effect of ionic strength on the adsorption of cationic polyelectrolytes onto alumina studied using electroacoustic measurements. Powder Technology, 113(1-2), 148-157. http://dx.doi.org/10.1016/S0032-5910(00)00225-4

Jia, L. W., Shen, M. Q., \& Wang, J. (2007). Preparation and characterization of dip-coated $\gamma$-alumina based ceramic materials on FeCrAl foils. Surface \& Coatings Technology, 201(16-17), 7159-7165. http://dx.doi.org/10.1016/j.surfcoat.2007.01.023

Jobson, E. (2004). Future challenges in automotive emmision control. Topics in Catalysis, 28(1-4), 191-199. http://dx.doi.org/10.1023/B:TOCA.0000024350.93474.d1

Kasprzyk-Hordern, B. (2004). Chemistry of alumina, reactions in aqueous solution and its application in water treatment. Advances in Colloid and Interface Science, 110(1-2), 19-48. http://dx.doi.org/10.1016/j.cis.2004.02.002

Kwade, A. (2004). Mill selection and process optimization using a physical grinding model. International Journal of Mineral Processing, 74, S93-S101. http://dx.doi.org/10.1016/j.minpro.2004.07.027

Kwade, A. (2003). A stressing model for the description and optimization of grinding processes. Chemical Engineering \& Technology, 26(2), 199-205. http://dx.doi.org/10.1002/ceat.200390029

Kwade, A., \& Schwedes, J. (2002). Breaking characteristics of different materials and their effect on stress intensity and stress number in stirred media mills. Powder Technology, 122(2-3), 109-121. http://dx.doi.org/10.1016/S0032-5910(01)00406-5

Kwade, A. (1999). Wet comminution in stirred media mills - research and its practical application. Powder Technology, 105(1-3), 14-20. http://dx.doi.org/10.1016/S0032-5910(99)00113-8

Nowack, B., Lutzenkirchen, T., Behra, P., \& Sigg, L. (1996). Modeling the adsorption of metal-EDTA complexes onto oxides. Environmental Science \& Technology, 30(7), 2397-2405. http://dx.doi.org/10.1021/es9508939.

Omura, N., Hotta, Y., Sato, K., Kinemuchi, Y., Kume, S., \& Watari, K. (2005). Characterisation of $\mathrm{Al}_{2} \mathrm{O}_{3}$ slurries prepared by wet jet milling. Journal of Ceramic Society of Japan, 113(7), 491-494. http://dx.doi.org/10.2109/jcersj.113.491

Sarraf, H., \& Herbig, R. (2008). Electrokinetic sonic amplitude measurement of concentrated alumina suspensions: effect of electrosteric stabilisation. Journal of Ceramic Society of Japan, 116(9), 928-934. http://dx.doi.org/10.2109/jcersj2.116.928

Tijburg, I. I. M., Geus, J. W., \& Zandbergen, H. W. (1991). Application of lanthanum to pseudo-boehmite and 
$\gamma-\mathrm{Al}_{2} \mathrm{O}_{3}$. Journal of Materials Science, 26(23), 6479-6486. http://dx.doi.org/10.1007/BF00551900.

Twigg, M. V. (2007). Progress and future challenges in controlling automotive exhaust gas emissions. Applied Catalysis B-Environmental, 70(1-4), 2-15. http://dx.doi.org/10.1016/j.apcatb.2006.02.029

Twigg, M. V. (2006). Roles of catalytic oxidation in control of vehicle exhaust emissions. Catalysis Today, 117(4), 407-418. http://dx.doi.org/10.1016/j.cattod.2006.06.044

Yang, Y. P., \& Sigmund, W. M. (2002). Expanded percolation theory model for the temperature induced forming (TIF) of alumina aqueous suspensions. Journal of the European Ceramic Society, 22(11), 1791-1799. http://dx.doi.org/10.1016/S0955-2219(01)00512-X 